\title{
WOOD ANATOMY NEWS and ASSOCIATION AFFAIRS
}

\section{New IAWA Council}

The composition of the new IAWA Council (2014-2017) following the elections earlier this year is given below. It nicely reflects the broad geographical and disciplinary diversity of our Association.

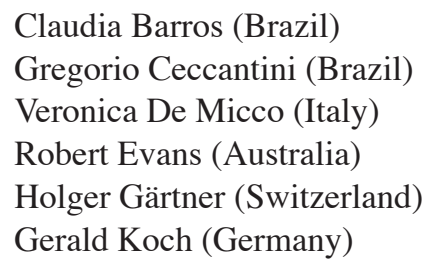

Biao Pan (China)

Fidel Roig (Argentina)

Rachel Spicer (USA)

Yasuhiro Utsumi (Japan)

Alex Wiedenhoeft (USA)

Yafang Yin (China)

The Council is the main governing body of IAWA (see http://www.iawa-website.org/ about.html), and also functions as editorial board of the IAWA Journal.

\section{New payment options IAWA dues}

In order to improve financial security and to make IAWA dues payments by credit cards easier for our members, we are currently working towards a web facility for membership renewal using PayPal. You will receive the following options to pay:

1. PayPal (credit cards only).

2. Bank transfer via your own bank.

3. For American members payment by check will remain possible.

Please take note of forthcoming e-mail messages from our financial officer, Cees Lut.

\section{IAWA Journal welcomes Letters, Opinions and Debate}

Wood anatomy in the framework of modern evolutionary, ecophysiological, and climate change research is at the same time a classical and yet very lively field. Several long-held beliefs and hypotheses are challenged by new analyses and experimental research. Apart from review papers and original studies in all these fields the IAWA Journal welcomes debate on these new developments, by starting a category of Letters, short publications voicing opinions and stimulating debate on current topics. Submitted letters will undergo a fast-track review and publication process and can be sent directly by e-mail to the editor-in-chief (pieter.baas@ naturalis.nl).

\section{Sherwin Carlquist's papers freely available}

Dr. Sherwin Carlquist's website (www.sherwincarlquist.com), devoted to his scientific work, now has downloadable pdfs of about 280 of his papers. In order to download any of these, go to the "Biography and Publications" section of the website. The papers for which pdfs are available, are mostly devoted to wood anatomy and wood evolution, and cover his publications from 1956 to the present. 


\section{Lively IAWA meetings in Padova}

IAWA can look back on a successful presence at the $9^{\text {th }}$ European PalaeobotanyPalynology Conference from 26-31 August 2014 in Padova, Italy. Marc Philippe and Jakub Sakala had organized a very interesting and well-attended symposium on "Fossil wood from taxonomy to paleo-ecological syntheses" on 28 August. In the evening of the same day, our local host Alan Crivellaro had organized an IAWA Social hour in the Secondo Piano restaurant overlooking the stunningly beautiful Piazza dei Signorii. Many IAWA Members and guests enjoyed the excellent wine and food that was generously provided in large quantities. IAWA was the only Publisher/Association granted a sales desk during the conference, resulting in very satisfactory book sales and assorted new membership applications.

Functional wood anatomy was also represented at various other sessions in the conference, leading to the initiative to aim for a comprehensive IAWA symposium on xylem strategies of land plants through time at the forthcoming Palaeobotanical World Congress in Salvador de Bahia, Brazil, in 2016.

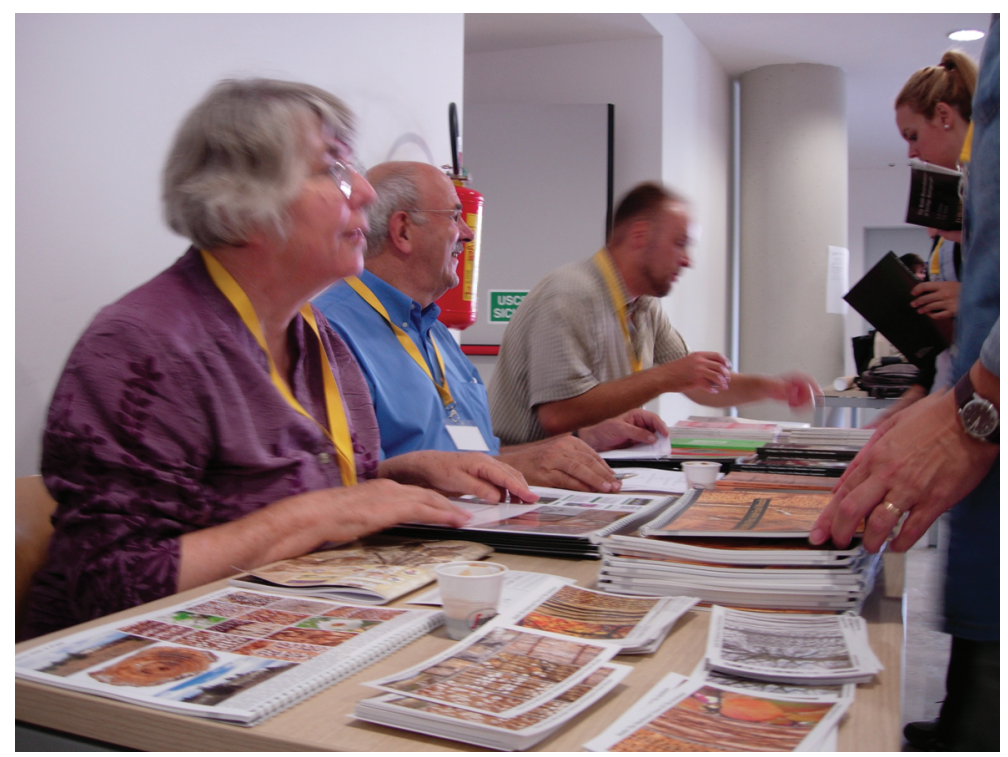

Elisabeth Wheeler, Pieter Baas and Jakub Sakala at the IAWA business table in Padova (by courtesy of Raymond van der Ham).

\section{Report from the IAWA activities in Salvador de Bahia}

The three IAWA-sessions on Thursday 23 October 2014, halfway the XIth Latin American Botanical Congress in Salvador de Bahia, Brazil brought together a large and interested audience to listen to and discuss presentations on dendrochronology, development and variation in the vascular system of plants, and systematics, evolution and ecology. 
Tree ring research is developing fast in Latin America, and is applied to climate change research as well as to forest management and protection in for instance the Amazon region where hydro-electric dams are an additional threat to the tropical lowland forest, not only by forest-to-reservoir conversion, but also downstream of the dams. The need to expand and intensify a tree-ring network across Latin America was stressed in the discussion. In the developmental and wood variability session interesting review papers on Neotropical woody plant studies alternated with original research papers on e.g. seedling and mature stems and cambial activity in cerrado species. Mark Olson's analysis on hydraulic optimization of vessel diameter in woody plants, concluding that, if scaled for total tree height or liana length, vessel diameter is not primarily governed by habit or habitat inspired a lively debate after the systematics and ecology session. The statement that in essence liana vessels are not wider than vessels of trees and erect shrubs was a shock to some, and will reverberate for a while, and definitely inspire interesting research in the future. Another paper of almost futuristic dimensions was on the xylotron, a portable device to identify wood in the field, using machine vision.

The IAWA day was concluded with a festive presentation of the bilingual Atlas of Wood Diversity in the Cerrado of São Paulo by Julia Sonsin, Peter Gasson, Silvia Machado, Caroline Caum and Carmen Marcati. The authors gracefully signed copies of their book, which sold like hot cakes. During coffee and lunch breaks IAWA represented by Vitor Barão and myself sold a number of IAWA publications and recruited seven new members to our association. Altogether a very successful and memorable wood anatomical event, for which we have to thank our local hosts Lazaro Benedito da Silva and Marcelo dos Santos Silva of the Universidade Federal da Bahia, and the other symposium organisers Fidel Roig and Carmen Marcati.

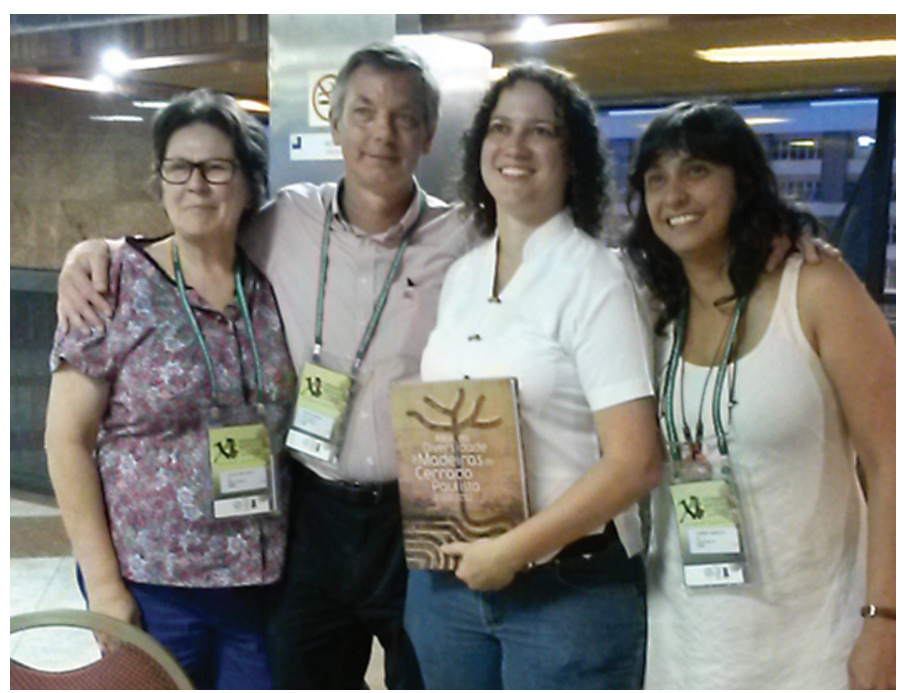

Four of the five authors at the launch of the Atlas of Wood Diversity in the Cerrado, from left to right: Silvia Machado, Peter Gasson, Julia Sonsin and Carmen Marcati, following the IAWA Symposia in Salvador de Bahia. 
On Friday 24 October, the IAWA officers present (Council Members, Conveners, Editors, Regional Group members) discussed association affairs during a productive working lunch in the Fiesta Bahia Hotel. Wood anatomically South America will be a busy continent the following years, with IAWA meetings foreseen in 2016 during the International Congress of Paleobotany and Palynology - again in Salvador de Bahia, in 2017 at the Congresso de Botânica in Rio de Janeiro, and in 2018 at the XIIth Latin American Botanical Congress (see also assorted news items in this column). Claudia Barros proposed the establishment of a Virtual Xylarium, including microscopic images, following the success of various Virtual Herbarium initiatives. Other topics discussed come back in some of the other news items in these pages. - Pieter Baas

\section{IAWA co-organizes the Tropical Forest Ecology Meeting in Tervuren}

From 26-29 May 2015 the international closing symposium of the XYLAREDD project "Wood science underpinning tropical forest ecology and management" will be held at the Royal Museum for Central Africa (Tervuren, Belgium). The Afro-European Group of IAWA and the IUFRO Unit 1.02.00 - Tropical and subtropical silviculture will act as co-organisers.

Background: Tropical forests and woodlands contain substantial carbon stocks, buffer climate change and produce raw material for local communities and international trade. The public concern for the fate of tropical forests resulted in the creation of a number of mechanisms assuring forests to sustainably produce valuable goods and services. One of the best-known mechanisms is the REDD+ mechanism of the United Nations aiming at the reduction of carbon emissions from deforestation and forest degradation. Since the Conference of Parties in Poznan in 2008, it comprises a chapter on sustainable tropical forest management. Another mechanism is the CITES convention regulating the international trade of endangered species, including important tropical timbers like American mahogany, afrormosia, ramin and some of the rosewoods and ebonies.

Next to REDD+ and CITES, several instruments have been established to conserve and manage tropical forests, their species and populations: some national forest laws, the FLEGT (Forest Law Enforcement, Governance and Trade) mechanism, the timber regulation of the European Union, the US Lacey Act and a number of forest and timber certification systems.

Sound forest management and effective conservation policies, including the ban of illegal logging, typically needs scientific information. Tools from the domain of wood science provide part(s) of this key information. Indeed, wood anatomy allows for verification of the authenticity of the material. The carbon sequestration processes can be evaluated by retrospective growth analysis performed on stem discs or wood cores. Finally, high-resolution data on wood density hold key information for the development of models on carbon stocks.

The objective of this international symposium is to explore how wood science can contribute to the needs of tropical forestry. We aim at bringing together wood and tropical forest scientists as well as policy makers and invite keynote speeches, oral presentations and poster sessions related to the following four subtopics: 
- Wood anatomy and other identification means for the enforcement of laws and regulations

- Wood density analysis to evaluate carbon stocks of tropical forests and woodlands

- Age determination, growth analysis and dendrochronology of tropical trees

- Wood anatomical functional traits to study and predict forest dynamics

For further information please contact: hans.beeckman@africamuseum.be

\section{Joint IAWA-IWCS meeting in Penn State University - July 2015}

At the invitation of the International Wood Collectors Society, IAWA has agreed to co-organize its Annual General Meeting at Penn State University from 23-26 July 2015. The theme will be "Back to School", and the full facilities of the university, including faculty and guest speakers will be used to "hold class" on both "wood science" as well as current research topics. It is also envisioned to have concurrent meetings in related fields such as forestry, bioenergy, lumber drying and grading, silviculture, etc. The role of IAWA members will include teaching microscopic and macroscopic wood courses and workshops, and lecturing on current topics in applied and fundamental wood anatomy research. Currently a planning committee is being formed. We will keep the IAWA Membership posted on new developments.

\section{WRAITH initiative}

Webster's dictionary defines wraith as an apparition or a ghost; in wood anatomy and forest conservation it stands for Wood Research Against Illegal Timber Harvest. Alex Wiedenhoeft from the Forest Products Laboratory in Madison Wisconsin presented his ideas on assembling an active group of wood anatomists within IAWA to help combat illegal logging with well-informed wood ID tools at the meeting of Salvador de Bahia. The network will include Vera Coradin (Brasilia), Peter Gasson (Kew), Gerald Koch (Hamburg) and many others. A formal proposal to the IAWA Council will follow. Watch out for further news or contact Alex (e-mail: acwieden@wisc.edu).

\section{Plants With A Past. Inside Fossil Woods}

This calendar is now available through Lulu Press. Each month features a different fossil wood locality or woody plant group and has multiple wood anatomical images for each month. Dates for Arbor Days around the world and World Wood Day are given so that you know of opportunities to celebrate trees (and their wood).

Profits from the sale of the calendar go to support fossil wood research and curating the InsideWood web site [http://insidewood.lib.ncsu.edu].

To order go to http://lulu.com and search for fossil wood or use the direct link to a page with a preview of all 12 months.

http://www.lulu.com/shop/elisabeth-wheeler/2015plants-with-a-past-inside-fossilwood/calendar/product-21881985.html

Lulu has stores outside the US - to find the store most convenient for you use the pull-down menu at the flag at the top right of the page. 


\section{I.W. Bailey Award 2015 - Call for nominations}

Irving Widmore Bailey (1884-1967) was one of the greatest wood anatomists of all time. His publications on xylem evolution, cambium and wood formation, cell wall ultrastructure, fossil woods, tree pathology, vestured pits, wood identification, and wood properties remain seminal to this day. His broad insights into the biological and practical significance of pattern and process in plant structure are still inspirational. IAWA honours his memory by naming the award for early career researchers, who publish their work in the IAWA Journal, after him.

From 2014 onwards, the I.W. Bailey Award is presented annually for the best original or review paper submitted to the IAWA Journal by a $\mathrm{PhD}$ candidate or postdoc who has completed her/his $\mathrm{PhD}$ no longer than five years since the submission of her/his manuscript. All subject matters published in the IAWA Journal are eligible: wood, bark, palm, bamboo, and rattan anatomy and ultrastructure, preferably linked to other fields such as, for instance, plant physiology, ecology, tree biology, pathology and decay, plant systematics and phylogeny, palaeobotany, climatology, archaeobotany, wood properties, biomechanics and wood culture. The Award consists of a certificate and 1000 USD, sponsored by Brill Publishers.

Candidates may nominate their own submissions directly to the editors of IAWA Journal (c/o pieter.baas@naturalis.nl), together with a one-page cv, and one supporting statement from a senior IAWA Member before September $1^{\text {st }}$ of the current year. Submissions will undergo the normal peer review process via the Brill/IAWA editorial manager system. The Award Committee will be formed by the Editors and Associate Editors of the IAWA Journal (please visit http://www.editorialmanager.com/iawa/ for instructions to authors).

The I.W. Bailey Award 2014 is currently being selected by the Award Committee and will be announced early 2015 . 


\section{Image Analysis for Forest Science}

\section{WinDENDRO ${ }^{\mathrm{TM}}$ Accurate Tree-Ring Analyser}

\section{Features}

$\checkmark$ Automatic ring detection with adjustable sensitivity $\checkmark$ Unlimited number of radii or paths can be created

$\checkmark$ Earlywood/Latewood boundary measured using density or light intensity

$\checkmark$ Multi-segment paths allow analysis of damaged disks,

curved cores or rings perpendicularly to their boundary

$\checkmark$ Ring-widths and Cross-dating graphics

$\sqrt{ }$ Correlation functions

$\sqrt{ }$ Tucson decadal formatted text file accepted as cross-dating reference

$\checkmark$ Smoothing spline curve can be displayed in order to choose the best parameters for detrending

$\checkmark$ Interactive quantification of compression and reaction wood

$\checkmark$ Wood density analysis using $\mathrm{x}$-ray films, digital $\mathrm{x}$-ray imaging, or the "Blue Intensity" reflected-light method

- Multiple density measurements can be saved on a ring or pixel basis

- Available per ring: ring width, earlywood and latewood width, ring maximum, minimum and mean density, earlywood and latewood mean density, and ring boundary orientation

- Available per pixel along a ring path: pixel density or light intensity, and slit orientation

$\checkmark$ XLSTEM $^{\mathrm{TM}}$ module available for stem analysis: mean radius, diameter and area per disk, tree height and volume as a function of age or year
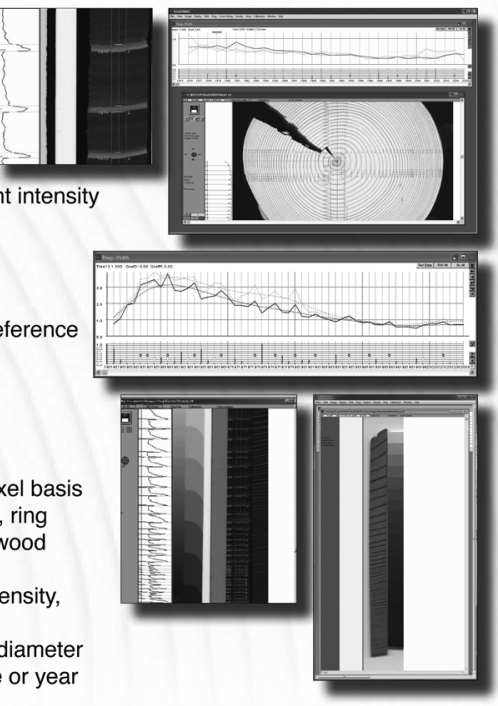

\section{WinCELL TM}

Specifically Designed for Wood Cell Analysis

\section{Features}

$\checkmark$ Anatomical analysis and quantification of wood cell structure parameters over annual rings:

- lumen area, perimeter, form coefficient

- lumen length and width

- wall thickness

- lumen and wall area in function of their color

$\checkmark$ Spatial distribution to analyse variations in function of cell position on annual rings

$\checkmark$ Flexible tools to exclude any image region from analysis $\checkmark$ Debris filtering

$\checkmark$ Analyses cells per annual ring for one or more rings per image

$\checkmark$ Data computed on a yearly basis in a format similar and compatible with WinDENDRO ${ }^{\mathrm{TM}}$

$\checkmark$ Integrated knowledge of wood cell anatomy and annual tree-ring formation produces data suited for wood scientists

$\checkmark$ Analyses images of thin wood slices mounted on a microscope with a camera or very high resolution images of regular wood cores or disks, or of woody roots (xylem) acquired with a scanner or a camera

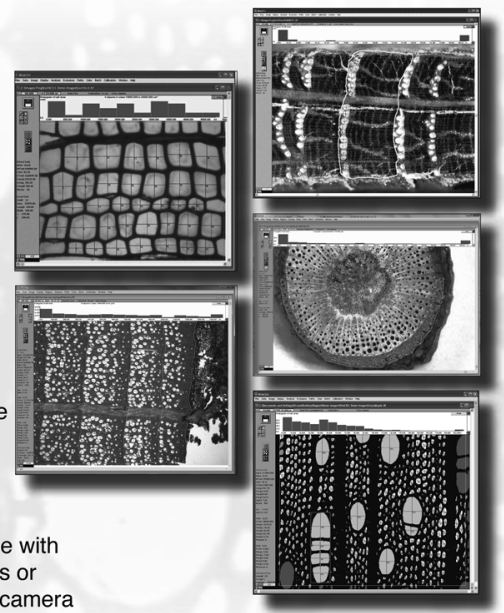

\section{징

